\title{
Valanko et al.: About Water Treatment (Book Review)
}

\author{
Christian Wolkersdorfer ${ }^{1}$ (D)
}

Published online: 14 April 2021

(c) Springer-Verlag GmbH Germany, part of Springer Nature 2021

About Water Treatment by Valanko R, Shestakova M, Pekonen P, Hesampour M, Hansen B, Halttunen S, Hofmann R, Pretorius R, Penttinen M, Recktenwald M, Karpova T, Rossum Rv, Grönfors O, Mattsson E, Ahlgren J, Nilsson B, Leen P, Havansi H, Abinet R (2020) About Water Treatment. Kemira Oyj, Helsinki

Seventeen years after its first edition, the chemical company Kemira Oyj from Finland, has released the second edition of its award-winning book "About Water Treatment." Both, the number of authors and the number of pages were substantially increased, as was the quality of the book. It also has a glossary now, which was missing in the first edition. Moreover, the book can be downloaded from the Kemira website for free (https://www.kemira.com/aboutwatertreat ment).

The book is divided into seven chapters with the titles: "Why do we need clean water?", "Drinking Water Treatment", "Waste Water Treatment", "Sludge Treatment", "Precipitation, Coagulation \& Flocculation", "Resource Efficiency", and "Smart Process Management". Each of the chapters describes in detail the technologies and their relevance to the water treatment process. Text as well as figures are nicely designed and written and allow the reader to easily understand the concepts and various steps of water treatment.

Though the book is not specifically written for mine water treatment, it includes many technologies that are relevant for understanding the processes and technologies used in mine water treatment. Mine water treatment is increasingly becoming relevant for chemical companies such as Kemira, so they included several sections covering mine effluents and their specific water treatment requirements in chapter 3 . These matters are discussed in context for specific metals,

Christian Wolkersdorfer

christian@wolkersdorfer.info

1 Department of Environmental, Water and Earth Sciences, SARChI Chair for Mine Water Management, Tshwane University of Technology (TUT), 175 Nelson Mandela Drive, Pretoria 0001, South Africa such as copper, gold, and iron (p. $123 \mathrm{ff}$ ). This is followed by describing some mine water treatment technologies and the chemicals that are commonly used in these processes (p. $127 \mathrm{ff}$ ). The authors correctly point out that "there are dozens of different treatment technologies available to water treatment plant operators, each with its own advantages, limitations, costs, reliabilities, and degree of effectiveness". On two pages, they briefly describe chemical precipitation, membrane technology, reverse osmosis, ozonation, and other treatment methods for mine water.

I found the excellent flow charts of the various treatment processes extremely helpful. They have been improved compared to the first edition (Fig. 1) by focussing only on relevant colours and lines, which better clarify the processes. Comparative flow charts have also been provided, where one can easily compare various treatment technologies and the time needed for the different treatment steps. Struvite precipitation is covered on two pages in the book, and the authors describe how it can be used and applied. As ammonia is also found in mine water, it would be advantageous if struvite could be produced through mine water treatmentunfortunately, my research group has not been successful so far in producing struvite from actual mine water.

A sentence that made me smile in this context is: "Since many fertilizers contain nitrogen and ammonia, the carbon content needs to be low; otherwise the fertilizer might be explosive (p. 262)". I imagined a virtual farmer spreading struvite on his farmland and accidentally blowing up his oat field.

Eleven interesting pages finish off the book (p. 269-280): "Smart Process Management" and "The Way Forward". In these chapters, the authors address the fourth industrial revolution and how it can be used to optimise water treatment by using the IoT (internet of things) and AI (artificial intelligence). They describe how smart technology will revolutionize (waste)water management and how the different layers in managing water will work together: automated dosing pumps (layer 1), accurate instrumentation (layer 2), real-time control loops (layer 2), IoT (layer 3), the data itself (layer 4), cloud-based servers (layer 5), versatile algorithms (layer 

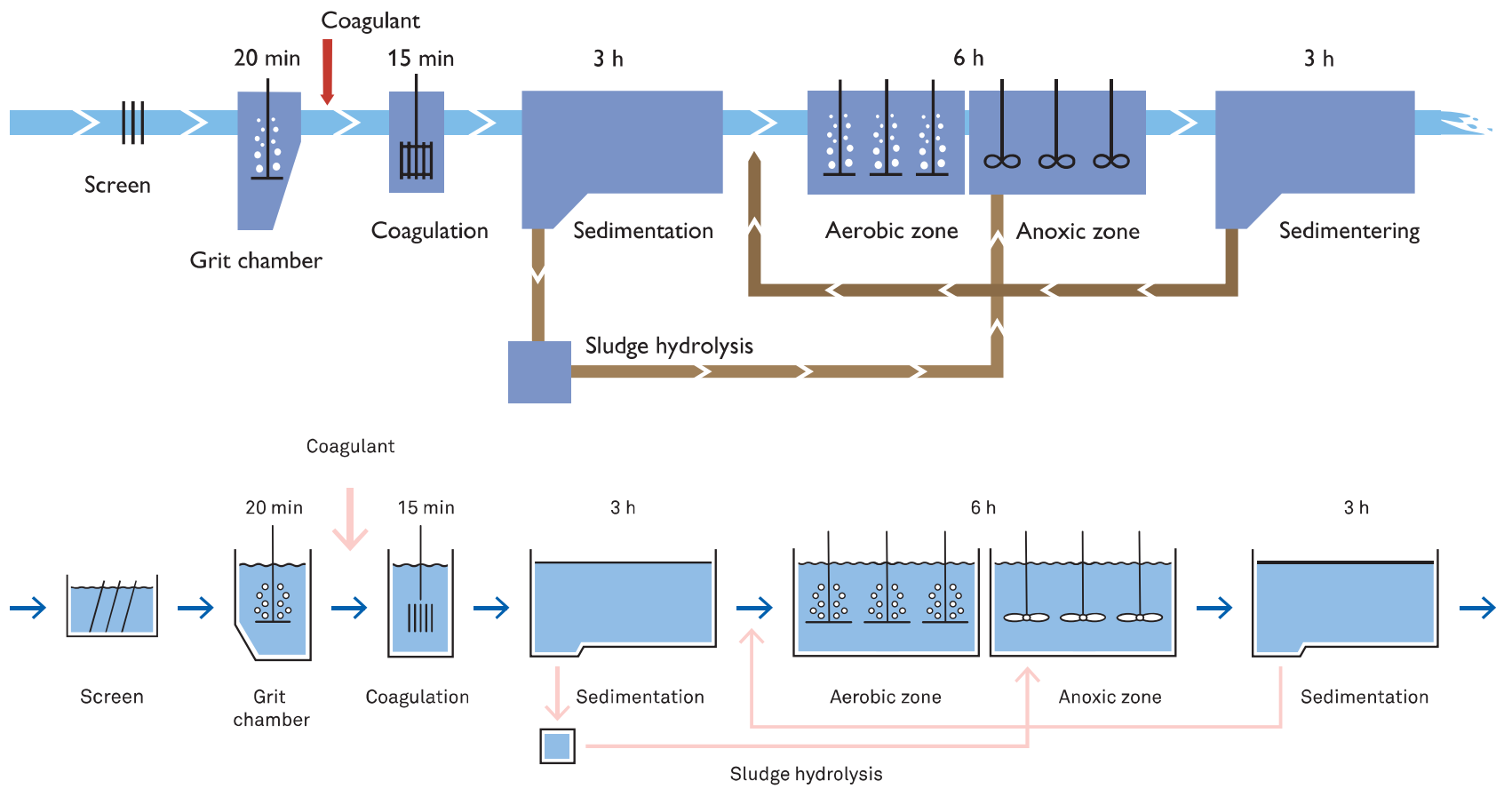

Fig. 1 Comparison of the treatment process flow charts in the first (top) and second edition (bottom) of "About Water Treatment". The second edition concentrates on the processes and less on the visual effects of the flow charts

5), and data security (layers 2-5). An interesting, not too often discussed concept they describe is using a digital twin, which can be considered a water management simulation of the processes. If done properly, all the details of a plant are well known before the real system goes into operation, by way of its digital twin.

Obviously, the book design has been optimised for hard copy reading, because the font is thin and hard to read on the screen. This is also true for the landscape format that they used, which leaves a lot of space in the upper section of the pages. Like the first edition, the book lacks an index and a reference section. Both issues make finding a relevant subject laborious, especially when using the printed version, and the missing references restrict the readers from following up on ideas that they might find relevant. Regrettably, the book also uses the unnecessary term "heavy metals", which is discouraged by the IUPAC (international Union of Pure and Applied Chemistry) and by the International Mine Water Association.
In summary, this book is easy to read, and explains the relevant steps and processes of water treatment. Therefore, this book can highly be recommended to everybody who wants to get a quick overview of water treatment technologies explained in a non-scientific way and even to experts who want to refresh their memory about one or another technology that they do not routinely work with. Personally, I found the descriptions about flocculants, flocculation, and coagulation extremely beneficial.

Let me finish this review with the authors' last paragraph: "Despite the many recent technological advances in the water treatment industry, business models remain largely unchanged. Smart process management should enable the development of new sustainable business models that take into account the overall value added throughout the process." 